\title{
Who uses marihuana for what ? \\ Results of survey on complementary and alternative medicine (CAM) use among patients with advanced cancer
}

Janusz Wojtacki ${ }^{1,2,{ }^{*}}$, Leszek Pawłowski ${ }^{2}$, Iga Pawłowska ${ }^{3}$, Monika Lichodziejewska-Niemierko ${ }^{2}$

1 - Hospice Foundation and Rev. Eugeniusz Dutkiewicz SAC Hospice, 2 - Department of Palliative

Medicine and 3 - Department of Pharmacology Medical University of Gdańsk, Gdańsk, Poland, * presenting author: janusz_wojtacki@hotmail.com

\section{Background}

- marihuana is used to control symptoms of advanced malignant disease and side effects of anticancer therapies

- data describing marihuana users are rather scarce

the aim of the study was to obtain information about the population of Polish patients who used marihuana as complementary and alternative (CAM ) therapy Methods

-semi-structured questionnaire about the usage of CAM was presented to all consecutive patients of Palliative Care Outpatient Clinic, Hospice Foundation and Rev. Eugeniusz Dutkiewicz SAC Hospice, Gdańsk, Poland (2016-2018)

-clinical data were collected at the same time, then statistically related to CAM use details

Results

the final analysis included 181 patients with advanced cancer and $55,8 \%$ ( $n=101)$ of them used at least one method of CAM therapy

basic demographic and clinical data of study populations are summarized in Figure 1.

Figure 1. Demographic and clinical data of study population $(\mathrm{N}=181)$.

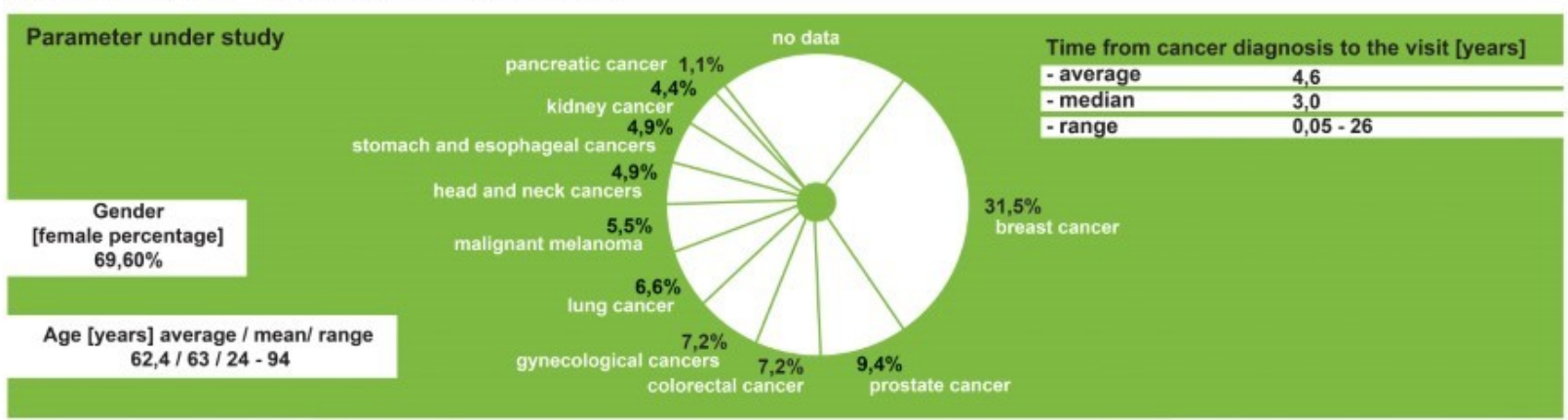

-only $11(10,9 \%)$ CAM-users declared marihuana use for 1 to 23 months (median: 3,5 )

- seven out of 11 patients noticed some improvement in symptoms control following marihuana usage

- there were some significant difference between marihuana users and those patients who did not choose marihuana as their CAM therapy -

Figure 2. summarizes those statistically significant results

Figure 2.: Characteristics of marihuana users versus no-marihuana users - differences of statistical significance.

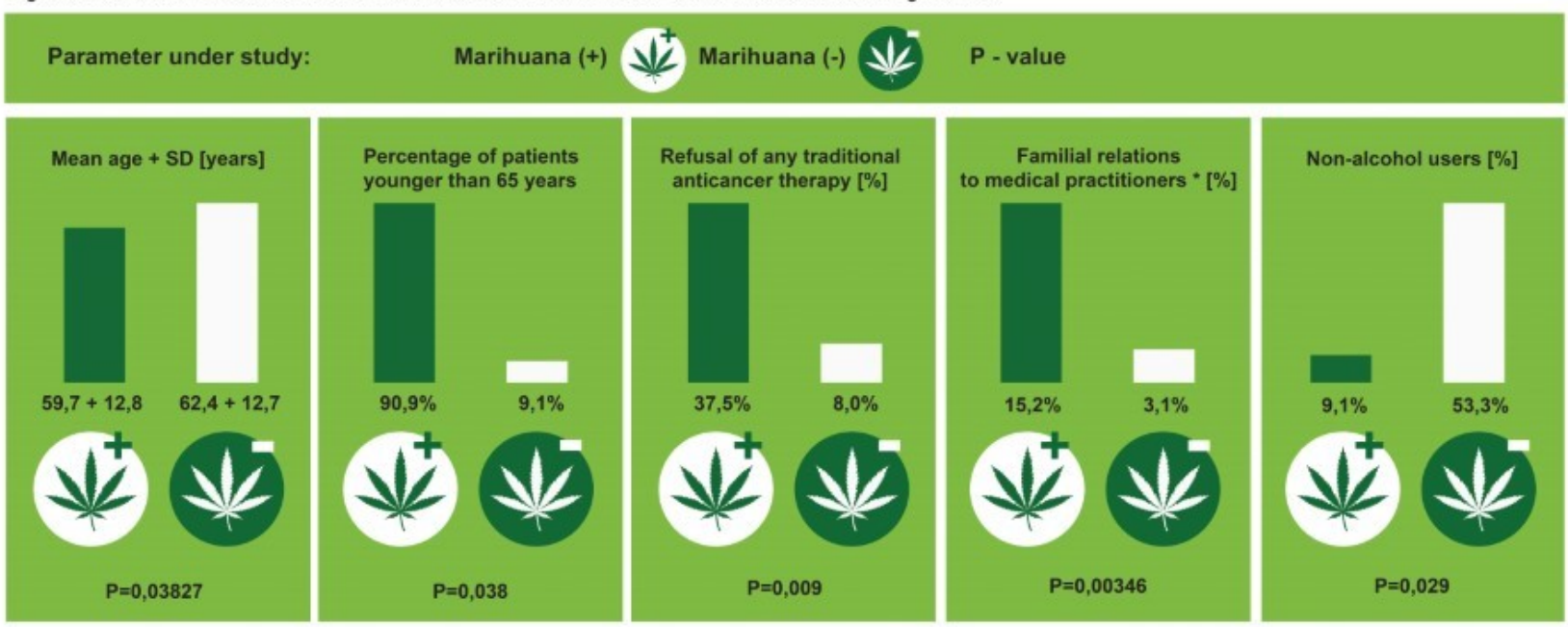

P - statistic significance; SD - standard deviation; NS - difference no statistically significant; " - doctor, nurse, pharmacist, physiotherapist, other

-in contrast, marihuana use was not significantly related to: gender, primary cancer location, educational level, marital status, professional activity, economic status, foreign stay over 6 months of the patient of his family member(s)

Conclusions

-marihuana is scarcely used for relieving symptoms in patients suffering from advanced cancer in Poland

-some factors seems to be related to marihuana use, but study should be continued for more reliable conclusions

-medical and health-care education appears to promote usage of various marihuana formulations 